\title{
Physician gender as a source of implicit bias affecting clinical decision-making processes: a scoping review
}

\author{
Tiffany Champagne-Langabeer* and Andrew L. Hedges
}

\begin{abstract}
Background: The demographic profile of practicing physicians is changing as more female medical students are graduating and practicing in the field. While the education received may not differ by gender, studies have shown that physician practice outcomes vary by provider gender. Various factors could contribute to these differences, including culture and explicit biases which may lead to implicit bias. This study aims to identify the available evidence of gender-based implicit bias throughout the delivery process of medicine.

Methods: This scoping review evaluated published literature within the PubMed, Ovid MEDLINE, PsychINFO, Web of Science, and BioMed Central databases pertaining to physician's gender as a factor in the delivery of medicine. Arksey and O'Malley's six-stage methodology was used as a framework and reported using the updated Preferred Reporting Items for Systematic reviews and Meta-Analyses extension for Scoping Reviews (PRISMA-ScR). Searches occurred between May 2020 and June 2020, and the timeframe was not limited. Included articles had gender as a factor in the delivery of medicine and implicit bias. Articles were excluded if they did not include the gender of the physician. After screening by reviewers and a medical librarian, study characteristics were charted and analyzed.
\end{abstract}

Results: The initial search resulted in 2420 records. After screening, 162 of the records were selected based on title and keyword relevance. After additional screening, 15 records were ultimately included in the review based on fulltext evaluation. Records were organized into sub-topics post hoc focused on clinical qualities, diagnostics, treatment, and outcomes.

Conclusion: This scoping review found that gender-based implicit bias may be inadvertently acquired from culture and education. Although implicit bias is highly researched, much of the current literature focuses on the gender of the patient. This study found important gaps in the available literature regarding race and gender of the physician. Further studies could explore outcome differences between recent graduates and career physicians, for both female and male physicians.

Keywords: Implicit bias, Gender medicine, Provider characteristics, Medical education

\footnotetext{
* Correspondence: Tiffany.Champagne@uth.tmc.edu

School of Biomedical Informatics, The University of Texas Health Science

Center, 7000 Fannin Street, Suite 600, Houston, TX, USA
}

(C) The Author(s). 2021 Open Access This article is licensed under a Creative Commons Attribution 4.0 International License, which permits use, sharing, adaptation, distribution and reproduction in any medium or format, as long as you give appropriate credit to the original author(s) and the source, provide a link to the Creative Commons licence, and indicate if changes were made. The images or other third party material in this article are included in the article's Creative Commons licence, unless indicated otherwise in a credit line to the material. If material is not included in the article's Creative Commons licence and your intended use is not permitted by statutory regulation or exceeds the permitted use, you will need to obtain permission directly from the copyright holder. To view a copy of this licence, visit http://creativecommons.org/licenses/by/4.0/ The Creative Commons Public Domain Dedication waiver (http://creativecommons.org/publicdomain/zero/1.0/) applies to the data made available in this article, unless otherwise stated in a credit line to the data. 


\section{Introduction}

Undergraduate medical education has experienced a plethora of new challenges which pose a significant social impact on the practice of medicine. Society places an unspoken moral contract on the profession of physicians, and the concept of medicine as both art and science further emphasizes the subjective nuances of care delivery [1]. Undergraduate medical education intertwines this sentiment defining medicine as “... a profession that incorporates science and the scientific method with the art of being a physician" [2]. There is a qualitative component of expertise which is indicated by the social skills involved in physician-patient interactions, and an intuitive sense involved in diagnostic decision-making. Within the modern healthcare environment, good medical practitioners understand how crucial and inseparable both aspects can be in patient outcomes [3]. Initiatives to demonstrate patient-centeredness require that physicians exercise their artistic capabilities while maintaining evidence-based practice guidelines [4]. This is partially in hopes of lowering health disparities affecting disenfranchised patients; however, evidence shows that many disparities persist today $[5,6]$. Several factors contribute to the presence and persistence of these disparities; however, it remains a challenge to promote awareness of bias while not assigning blame [7]. While it is the rigor of science and research that develops clinical practice guidelines, it is the art and judgment of an individual physician which impacts the patient.

Within the context of healthcare, the concept of prejudice, or perceived feelings regarding a patient based upon certain characteristics such as race, gender, ethnicity, sexual orientation, or other variables, is considered negative and is discouraged within the medical profession $[8,9]$. However, implicit bias-defined as preferential associations that exist subconsciously-is subtle and harder to detect [10]. In psychological terms, implicit bias can be viewed as a latent or subconscious construct. In this way, a physician with an (unrealized) implicit bias against patients who use heroin may create preconceived judgments about the patient's ability to adhere to medication. This may or may not change their behavior towards the patient. Thus, implicit bias may be described in terms of the resultant behavior: the decision made by the physician [11]. There are assessments for measuring implicit bias such as the Implicit Assessment Test (IAT); however, this assessment intends to measure the deeply held beliefs which do not necessarily translate into action [12, 13]. The IAT in vignette-based studies has shown mixed results, with implicit bias correlating to action or having no relationship to outcomes [14]. The definition by De Houwer and colleagues of implicit bias as a "behavioral phenomenon" may prove more useful, as measuring a subconscious and often unrealized construct in the absence of action proves challenging and often unreliable [11].
Implicit bias may be observed through the actions of physicians as well as patients. Prior studies have shown some medical professionals have a preference for others who resemble their own ethnicity and skin tone [15]. Similarly, African American patients who feel disenfranchised by the healthcare system, prefer a physician of their own race [16]. Akin to implicit bias, the fear of stigma may cause lesbian, gay, bisexual, and transgendered (LGBT) patients to withhold certain information from caregivers due to mistrust of medical providers or fear of discrimination $[17,18]$.

Medical schools graduate more female physicians than at any time before in their histories, which brings forth the topic of gendered medicine [19]. Many institutions and medical centers hire more female physicians, rejecting inaccurate, institutionalized explicit biases [20]. However, women persist in small numbers in positions of leadership, especially at the executive or dean level with only $16 \%$ representation [21]. There are negative implications to an unbalanced leadership hierarchy. Organizational structures tend to perpetuate themselves; therefore, without conscious interventions in place, men are promoted more often than women [22]. The secondary effect on the medical student population is one which projects the subliminal message of who is accepted and most likely to succeed [23]. A dearth of females in positions of authority or influence can reduce the potential for scientific discovery, as females are more likely to develop new programs related to women's health [24, 25]. Prior research has addressed the impact of increased diversity and specific metrics were reviewed as more favorable when female physicians were caring for patients within management [26] and overall wellbeing [27]. However, due to the subjective nature of clinical decision-making, no consensus on a primary determinant exists for the differences seen in real-world medical practice [28].

The impact of gender on medical decision-making has traditionally focused on the physicians' perceptions of their patients. A review of research in cardiovascular health highlights differences in the clinical presentation, subsequent diagnosis, and reveals the existent gendergap in patient outcomes in sophisticated modern health systems $[29,30]$. Differences in the management of cardiovascular health also show gender-based biases when making decisions for treatment, but the results are mixed. In one study, both male and female physicians performed fewer cardiac catherizations on female patients; however, the same study showed that female physicians performed fewer procedures in general when compared with male physicians [31]. In a separate study, male patients were seen as strong and greater value was placed on stress tests and angiography, while female patients were seen as risk-averse by both male and female 
cardiologists [32]. The reasons for treatment variations not explained by gender are valid differences in clinical presentation between men and women including women have a higher incidence of ischemic stroke; whereas, men are more prone to myocardial infarctions [33]. Aside from clinical presentation, some studies have attributed downstream differences in physician behavior to the training received in medical school, residency, internships, and other phases in medical education [34], while others assert the workplace as a contributing factor [35]. A review of the research shows the impact of patient gender on clinical decisionmaking and the implicit biases associated are multifactorial.

In the medical field, the downstream effects of negative implicit bias can contribute to increased medical costs or death [27]. To date, much of the research related to implicit bias occurring within healthcare has focused on the gender of the patient as opposed to the gender of the physician. And while many within the medical field recognize gender-based differences between the practices of male and female physicians, no comprehensive review exists that explores the breadth of these provider differences and the origin of gender-based implicit bias. This scoping review attempts to answer two questions: 1) what implicit biases exist between male and female physicians; and 2) how do the coinciding implicit biases manifest in clinical behavior, performance, and outcomes. This scoping review aims to address the lack in available knowledge by coalescing existing publications and perspectives, in hope of describing gender-based clinical decision-making within the physicians' daily practice.

\section{Methods}

\section{Record selection}

In contrast to systematic reviews, scoping reviews address gaps in knowledge while developing additional research questions within a particular topic of interest [36]. This research followed Arksey and O'Malley's framework [37] and was reported using the updated Preferred Reporting Items for Systematic reviews and MetaAnalyses extension for Scoping Reviews (PRISMA-ScR) checklist [38]. The methodology was established in a stepwise manner. First, the research questions were identified. Next, a medical librarian assisted in identifying relevant search terms, exploring research databases, and refining the criteria for record inclusion. Third, a review of abstracts of relevant, selected records occurred. Articles included were available in the English language. (Fig. 1). Next, the selected full-text articles were

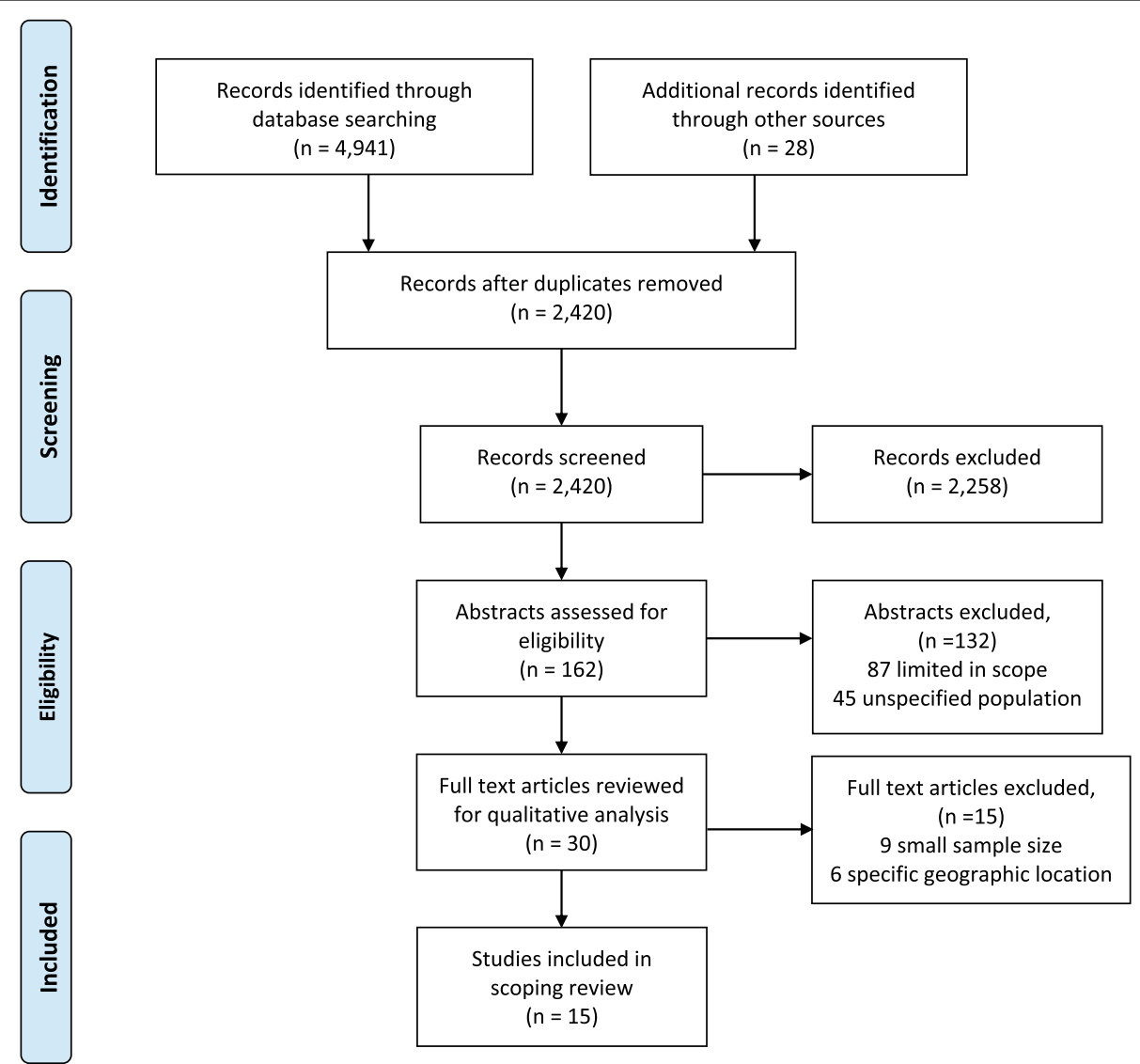

Fig. 1 Article Search and Review Process 
reviewed, charted, and the results synthesized. Lastly, the studies were organically grouped based on relevance to various subtopics in order to illuminate insights from the literature.

The initial strategy for finding relevant published records included use of the PubMed, Ovid MEDLINE, and PsychINFO databases. Secondary searches followed within BioMed Central and the Web of Science databases. A large range of search terms were needed to define relevance criteria, both during the search and while evaluating the accompanying results. Select keywords and phrases included: 'provider sex', 'physician sex', 'practice patterns', 'clinical decision making', 'gender concordance', 'sex-based differences', and 'implicit bias'. A complete list of terms in included in Appendix A. These searches occurred between May 2020 and June 2020 , and the timeframe of when the articles were published was not limited.

Both authors reviewed abstracts from the keyword and medical subject heading (MeSH) search then met to determine articles for full text review. Both authors reviewed the subsequent full text selection, and disagreements were handled by a third reviewer (the medical librarian). After completing the selection process for inclusion in the next stage, the level of relevance for the resulting records occurred by assessing the title, keywords, and abstract. Those without obvious relevance to the research question were excluded from further analysis. Determination of exclusion occurred with conservative judgment; therefore, records of questionable status would still undergo analysis. During the evaluation of the literature, some criteria were mandatory, including mention of implicit bias and gender-based topics.

Once all publications were selected, appropriate study details were charted and stored in a database, including the primary author's name, study design, publication year, subject (physician specialty or disease), relevant findings, and a short summary of the study. After completing the charting form, the records were classified based on connections and similarities to a variety of subtopics within gender-based implicit bias in the clinical decision-making process. Each record received a tag to one of four sub-topics which were determined post hoc based on attributable, gendered differences in a variety of settings. (PRISMA-ScR Checklist available as a Supplementary file.)

\section{Group definitions}

A scoping review differs from a systematic review in its intent to survey a specific field of study, identify gaps, then collate and disseminate the relevant findings; as such, there is no intention to provide a weighted, evidenced based approach in view of the results [37, 39].
After reviewing and selecting relevant literature, an analytical framework of broad, sub-topic categories was employed to further assemble the narrative presentation. The Clinical Qualities sub-topic was chosen to aggregate the studies that best represented aspects of healthcare involving medical culture, education, and other preclinical factors. Diagnosis of Disease and Treatment of Disease represented differences in clinical behavior and decision-making. Two discrete categories were used to describe behavioral differences in which the disease or condition was not known (Diagnosis) against when the complaint was known (Treatment). Lastly, the Outcomes sub-topic focused on the post-clinical, downstream effects of gender-based, implicit biases on modern medicine.

\section{Results \\ Record analysis}

The initial search of literature resulted in 2420 records. After screening, 162 of the records were selected for additional analysis, based on title and keyword relevance. Records were excluded from the primary round of screening, because they were the wrong subject, not focused on the delivery of healthcare, or did not study the gender of the physician. After this first round of exclusion, subsequent analysis of abstracts resulted in the rejection of 132 additional records. Of the remaining 30 records, 15 were ultimately included in the scoping review based on full-text evaluation. These 15 records were then organized into the sub-topics: 5 focused on clinical qualities, 4 on diagnosis of disease, 4 on treatment differences, and 2 on outcome differences.

\section{Record characteristics}

The 15 records in this study were published between 2004 and 2020, with $67 \%$ majority being published after 2015 (Table 1). The origin for most of the records was the United States (60\%). The remaining records either originate in Western European countries (33\%) or Canada (7\%). Regarding subject matter, most records focused on generalized medicine/training (53\%), followed by specialty or subspecialty focused practices (47\%). All records, except the systematic review by Chapman and colleagues (2013) and the perspective piece by Hemphill and colleagues (2020), were primary studies on the effects of implicit bias, gender, and the clinical decisionmaking process of physicians. Many of the primary research records were prospective in study design (62\%); the remaining records utilized a retrospective approach through electronic health record extraction or use of publicly available and verified datasets (38\%). 
Table 1 Literature concerning implicit bias and clinical decision making

\begin{tabular}{|c|c|c|c|c|c|}
\hline & Study Author(s) & Study Design & Study Participants & Specialty/Focus & Relevant Finding \\
\hline \multirow[t]{5}{*}{ Clinical Qualities } & Amoli et al. 2016 [20] & Survey & $N=503$ & Pediatric Orthopedics & $\begin{array}{l}\text { Changes in demographic make-up } \\
\text { of pediatric orthopedics indicate } \\
\text { higher hiring rate for females. }\end{array}$ \\
\hline & Hemphill et al. 2020 [34] & Perspective & $\mathrm{n} / \mathrm{a}$ & Medical Education & $\begin{array}{l}\text { Physicians may acquire gender- } \\
\text { based implicit biases through } \\
\text { educational and formative } \\
\text { experiences. }\end{array}$ \\
\hline & Ferguson et al. 2018 [28] & $\begin{array}{l}\text { Prospective } \\
\text { validation }\end{array}$ & $N=247$ & $\begin{array}{l}\text { Cardio-/Thoracic } \\
\text { surgeons }\end{array}$ & $\begin{array}{l}\text { Outcomes of clinical vignettes } \\
\text { do not show implicit bias. }\end{array}$ \\
\hline & Furnas et al. 2018 [40] & Survey & $N=757$ & Plastic surgeons & $\begin{array}{l}\text { Women demonstrated a higher } \\
\text { perception of gender concordance } \\
\text { with their patients. }\end{array}$ \\
\hline & Greene et al. 2018 [41] & Survey & $N=915$ & Clinical Preferences & $\begin{array}{l}\text { Patients may have an implicit } \\
\text { bias based solely on name } \\
\text { when selecting a physician. }\end{array}$ \\
\hline \multirow[t]{4}{*}{ Diagnosis of Disease } & Berthold et al. 2008 [42] & Cross-sectional & $N=51,053$ & GPs/Internists & $\begin{array}{l}\text { Patients of female physicians } \\
\text { received higher quality of care for } \\
\text { Diabetes Mellitus Type II. }\end{array}$ \\
\hline & Bouck et al. 2018 [26] & Cohort & $N=2394$ & GPs & $\begin{array}{l}\text { Male physicians order more low- } \\
\text { value tests than female physicians. }\end{array}$ \\
\hline & Hamberg et al. 2004 [43] & Case Description & $N=289$ & $\begin{array}{l}\text { Gastrointestinal } \\
\text { Specialists }\end{array}$ & $\begin{array}{l}\text { Physicians utilize different gender } \\
\text { cues during the clinical work-up } \\
\text { and diagnosis of gastrointestinal } \\
\text { disease. }\end{array}$ \\
\hline & Bernardes et al. 2013 [44] & Between Subjects & $N=310$ & GPs & $\begin{array}{l}\text { Physician-held stereotypes to } \\
\text { gender may influence the } \\
\text { diagnosis and treatment of } \\
\text { low-back pain. }\end{array}$ \\
\hline \multirow[t]{4}{*}{ Treatment } & Daugherty et al. 2017 [32] & $\begin{array}{l}\text { Prospective } \\
\text { validation }\end{array}$ & $N=503$ & Cardiologists & $\begin{array}{l}\text { Female physicians show lower } \\
\text { gendered implicit bias than males. }\end{array}$ \\
\hline & Hirsh et al. 2014 [35] & $\begin{array}{l}\text { Analog Design } \\
\text { (simulation) }\end{array}$ & $N=98$ & GPs & $\begin{array}{l}\text { Provider sex is an influence on } \\
\text { the selection of treatment option. }\end{array}$ \\
\hline & Sabin et al. 2009 [45] & Survey & $N=2535$ & Medical Doctors & $\begin{array}{l}\text { Only Black female physicians } \\
\text { showed no implicit bias towards } \\
\text { male or female patients. }\end{array}$ \\
\hline & Schwartz et al. 2003 [46] & Survey & $N=289$ & Obesity experts & $\begin{array}{l}\text { Female physicians were more } \\
\text { likely to associate the word "fat" } \\
\text { with bad, lazy, and stupid but not } \\
\text { "worthless". }\end{array}$ \\
\hline \multirow[t]{2}{*}{ Outcomes } & Chapman et al. 2013 [5] & Perspective & $\mathrm{n} / \mathrm{a}$ & $\begin{array}{l}\text { Systematic review } \\
\text { of literature }\end{array}$ & $\begin{array}{l}\text { Implicit bias within physicians } \\
\text { leads to perpetuating health } \\
\text { care disparities. }\end{array}$ \\
\hline & Tsugawa et al. 2017 [27] & $\begin{array}{l}\text { Retrospective } \\
\text { Analysis }\end{array}$ & $\begin{array}{l}N=1,583,028 \\
\text { (episodes of care) }\end{array}$ & Internists & $\begin{array}{l}\text { Female internists treat elderly } \\
\text { hospitalized patients in a manner } \\
\text { that lowers 30-day readmission } \\
\text { rates and decreases hospital- } \\
\text { related death. }\end{array}$ \\
\hline
\end{tabular}

GPs, General Practitioners

\section{Clinical qualities}

Beginning with undergraduate and graduate medical educations, differences exist through negative perceptions, systematic favoritism, and historic biases in teaching style. Hemphill and colleagues found that female surgical residents required one-on-one facilitation while male residents performed better with repeat practice when learning surgical skills [34]. Outside of this intervention, males outperformed their female counterparts leading to a perception of increased and innate ability. In a study conducted by the American Society of Plastic Surgeons, although equally satisfied with their career choice, females were more likely to be single and not engage in hobbies when compared with their male counterparts [40]. However, measuring gender-based clinical differences is challenging. In a study of cardiothoracic 
surgeons, more men self-identified as "expert" and women as "competent"; yet, reviews of clinical vignettes did not show differences in their evaluations of patients [28]. Further regarding the medical work culture, an examination of how gender affects the demand and load of a surgical schedule does not reflect the equality and equity that female physicians have achieved in recent years. Female surgeons report lower salaries overall when compared with men, but this may be due in part to the decision to work less hours or take fewer cases [20]. However, one study hypothesized the salary disparity may be attributable in part to the fact that some patients make physician selections based solely on the perception of gender and race, favoring male and white sounding names despite treatment or satisfaction ratings [41].

\section{Diagnosis of disease}

Gender-based differences exist within a variety of diagnostic performance categories. Beginning with obtaining and interpreting a health history, female physicians were more likely to factor in past medications and psychosocial health when diagnosing disease; while male physicians were more likely than female physicians to ask male patients about tobacco and alcohol use [43]. Further results found that male physicians placed more emphasis on the visibility and objectivity of patient symptoms when judging pain credibility and when making referral decisions to a psychologist or psychiatrist [44]. For certain conditions, like Diabetes Mellitus, diagnosis and prevention tend to be more comprehensive when performed by female physicians. In a large crosssectional study $(n=51,053)$, patients of female physicians were more likely to maintain control of blood pressure, glycemic control, and blood lipoproteins [42]. Generalized diagnostic tests also show gendered differences, with older male physicians ordering more low-value screens and tests in low-risk patients (e.g., chest radiographs, Papanicolaou test, repeat dual-energy x-ray absorptiometry, and repeat electrocardiograms) compared to their female counterparts [26].

\section{Treatment of disease}

Within the management and treatment of disease, physician gender influences a variety of factors. Female physicians were more likely to prescribe psychosocial therapies and medications than male physicians, even when bias for sexism was controlled using the Ambivalent Sexism Inventory scale $[35,47]$. In the treatment of disease, evidence shows marked differences in the judgment of male physicians regarding male patients. Male patients were viewed as stronger and more open to risk regarding invasive treatments such as angiograms; however, gender of the physician was not significant when making treatment decisions after an abnormal exercise treadmill test or when recommending secondary diagnostic tests [32]. Treatment decisions may be influenced by the race of the patient, as well as the gender of the physician. In a large study of physicians $(n=2535)$ who completed the Race Attitude Implicit Associations Test [48], both genders displayed a preference for White Americans. However, when race and gender of the physician were tested, only female Black physicians displayed no implicit bias [45]. Implicit bias may translate into patient experience. All physicians surveyed reported significant anti-fat bias, but female physicians were more likely to associate the word "fat" with "bad", "lazy", or "stupid" [46].

\section{Outcomes}

The effects of gender-based, implicit bias were also realized at the population level, with evidence suggesting that Medicare patients treated by male physicians have increased healthcare costs, adverse outcomes, and chance of hospital-related death compared to those treated by female physicians [27]. A study which investigated the origins of both implicit (latent) beliefs and explicit (or controlled) actions found that while more obvious acts of prejudice may evolve over time, the behavior which results from implicit bias may persist and influence decision making [5]. However, the study also found that trainings and facilitating a culture of bias literacy can aid in reducing outcome disparities in both the educational and clinical setting [5].

\section{Discussion}

This scoping review of the literature on physician gender as a source of implicit bias suggests there are differences which exist between male and female physicians with respect to clinical decision making in some areas of practice; and these biases may manifest in behavioral performance and outcomes. When considering the role that a physician's gender may have in the clinical decision-making process, studies which attempt to qualify causative factors were varied. Despite this challenge, this scoping review attempted to explore various manifestations within the context of medical education [34], culture $[20,40,41]$, practice $[26,32,35,42-44]$, and outcomes [5, 27]. Within modern medical practice and culture, recognizing the important role of gender may serve as benefit to patient outcomes and satisfaction [49]. Despite best attempts at ensuring equity of care, accounting for physician differences, implicit biases are likely a source of continued medical disparities [28].

Reducing the burden of implicit bias is a highly researched topic with regards to the race and gender of the patient; however, this study found important gaps in the available literature regarding physician race and gender $[5,50]$. Much of the literature on gender and 
decision-making highlights the disparities and ensuing effects on the treatment of female physicians in the workforce, and demonstrates that implicit bias may be inadvertently acquired and maintained from culture and education. One manner for reducing negative outcomes includes conceptualizing implicit bias as a manner of thinking that must first be recognized before it can be altered [51]. This can be achieved through pattern and cognitive recognition practices. Individuating, or making an active effort to focus on individual characteristics of patients, may mitigate the effects of implicit bias [5]. However, this strategy may be too time-intensive for modern medicine. Certain skills, such as self-awareness and critical reflection, can also aid in the reduction of implicit bias, thereby improving the relationship and subsequent outcomes of the patient and physician [52]. Reducing the "hidden agenda" that some medical institutions inadvertently perpetuate through structured coursework or lectures may reduce implicit biases [52]. Alternatively, trainings which include priming physicians with positive words, images, or videos could also be an adequate strategy in high-pressure or time-demanding practice situations [50].

Increasing the number of female physicians in positions of leadership may dull the pervasive impacts of implicit bias in clinical decision making by providing cognitive diversity and different viewpoints [53]. Strong role models are needed to provide a source of confidence and a pathway to leadership for younger physicians, in an environment where $44 \%$ of females see their gender as harmful to their status as a potential leader [54]. Through the review of literature, gender-based research is a provocative and relevant subject, evidenced by the increased number of studies published within the last decade. However, a majority of the research published in this domain focuses on patient rather than provider's gender. This scoping review is novel in that it focuses on the physician's gender as a contributing factor to clinical practice.

In interpreting the results of this scoping review, however, some limitations should be considered. First, despite attempts to perform an extensive and comprehensive search, there may be records that were never identified or inadvertently removed from the review process. Additionally, no unpublished studies were included in this review, so it is possible that new research on implicit bias could exist. Secondly, filtering for the reviewed articles required several necessary terms be present, including implicit bias and gender-based phrasing. This may have been too limiting, as there are alternative ways of describing implicit bias without overtly mentioning it. Lastly, as in many domains where more positive or provocative results are desired, there is a risk for publication bias. Our search terms could have influenced the publications ultimately selected for this scoping review, or there may be a lack of publications showing opposite effects.

\section{Conclusion}

Despite these shortcomings, the findings from this scoping review suggest that gender-based implicit bias may affect the decision-making processes of physicians in the real world. These findings pertain to the diagnosis, treatment, and overall outcomes of disease. However, much is still unknown about the effect of the physician's gender on their clinical decision-making processes. Further studies could explore outcome differences between recent graduates and career physicians, for both female and male physicians. Future research should explore differences in decision making between male and female physicians in healthcare environments where female role models are present in positions of leadership in order to test hypothesized changes in behavior.

\section{Abbreviations}

AAMC: Association of American Medical Colleges; GP: General practitioner; MeSH: Medical subject heading

\section{Supplementary Information}

The online version contains supplementary material available at https://doi. org/10.1186/s12909-021-02601-2.

\section{Additional file 1.}

Additional file 2.

\section{Acknowledgements}

The authors would like to recognize assistance from Texas Medical CenterHouston Academy of Medicine librarian Travis Holder, who assisted in generating search terms specific to the research question.

\section{Authors' contributions}

$\mathrm{TCL}$ and $\mathrm{AH}$ conceptualized the topic, collaborated on inclusion and exclusion criteria, and reviewed articles. AH wrote the first draft; and $\mathrm{TCL}$ edited and approved the final submission. The author(s) read and approved the final manuscript.

\section{Funding}

There were no sources of funding for this scoping review.

Availability of data and materials

Datasets generated during this study are included in the published article.

\section{Declarations}

Ethics approval and consent to participate

Not applicable.

Consent for publication

Not applicable.

Competing interests

The authors report no competing interests. 


\section{Received: 10 September 2020 Accepted: 8 March 2021} Published online: 19 March 2021

\section{References}

1. Cruess RL, Cruess SR. Expectations and obligations: professionalism and medicine's social contract with society. Perspect Biol Med. 2008;51(4):579_ 98. https://doi.org/10.1353/pbm.0.0045.

2. Goldman L, Schafer Al. Goldman-Cecil medicine. 26th edition. Philadelphia: Elsevier; 2020.

3. Panda JC. Medicine: science or art? Mens Sana Mongraphs. 2006;4(1):12738. https://doi.org/10.4103/0973-1229.27610.

4. Greene SM, Tuzzio L, Cherkin D. A framework for making patient-centered care front and center. Perm J. 2012;16(3):49-53.

5. Chapman EN, Kaatz A, Carnes M. Physicians and implicit bias: how doctors may unwittingly perpetuate health care disparities. J Gen Intern Med. 2013; 28(11):1504-10. https://doi.org/10.1007/s11606-013-2441-1.

6. Singh GK, Daus GP, Allender M, Ramey $C T$, Martin EK, Perry C, Reyes AAL, Vedamuthu IP. Social determinants of health in the United States: addressing major health inequality trends for the nation, 1935-2016. Int J MCH AIDS. 2017;6(2):139-64. https://doi.org/10.21106/ijma.236.

7. Zestcott CA, Blair IV, Stone J. Examining the presence, consequences, and reduction of implicit Bias in health care: a narrative review. Group Process Intergroup Relat. 2016;19(4):528-42. https://doi.org/10.1177/1368430216642 029.

8. Jagsi R, Griffith KA, Jones R, Perumalswami CR, Ubel P, Stewart A. Sexual harassment and discrimination experiences of academic medical faculty. JAMA. 2016;315(19):2120-1. https://doi.org/10.1001/jama.2016.2188.

9. Fnais N, Soobiah C, Chen MH, Lillie E, Perrier L, Tashkhandi M, Straus SE, Mamdani M, al-Omran M, Tricco AC. Harassment and discrimination in medical training: a systematic review and meta-analysis. Acad Med. 2014; 89(5):817-27. https://doi.org/10.1097/ACM.0000000000000200.

10. FitzGerald C, Hurst S. Implicit bias in healthcare professionals: a systematic review. BMC Med Ethics. 2017;18(1):19. https://doi.org/10.1186/s12910-0170179-8.

11. De Houwer J. Implicit Bias is behavior: a functional-cognitive perspective on implicit Bias. Perspect Psychol Sci. 2019;14(5):835-40. https://doi.org/10.11 77/1745691619855638.

12. Greenwald AG, McGhee DE, Schwartz JL. Measuring individual differences in implicit cognition: the implicit association test. J Pers Soc Psychol. 1998; 74(6):1464-80. https://doi.org/10.1037/0022-3514.74.6.1464.

13. Schimmack U. The Implicit Association Test: A Method in Search of a Construct [published online ahead of print, 2019 Oct 24]. Perspect Psychol Sci. 2019;1745691619863798. https://doi.org/10.1177/1745691619863798.

14. Maina IW, Belton TD, Ginzberg S, Singh A, Johnson TJ. A decade of studying implicit racial/ethnic bias in healthcare providers using the implicit association test. Soc Sci Med. 2018;199:219-29. https://doi.org/10.1016/j. socscimed.2017.05.009.

15. Gonzalez CM, Kim MY, Marantz PR. Implicit bias and its relation to health disparities: a teaching program and survey of medical students. Teach Learn Med. 2014;26(1):64-71. https://doi.org/10.1080/10401334.2013.857341.

16. Chen FM, Fryer GE, Phillips RL, Wilson E, Pathman DE. Patients' beliefs about racism, preferences for physician race, and satisfaction with care. Ann Fam Med. 2005;3(2):138-43. https://doi.org/10.1370/afm.282

17. Matthews AK, Peterman AH, Delaney P, Menard L, Brandenburg D. A qualitative exploration of the experiences of lesbian and heterosexual patients with breast cancer. Oncol Nurs Forum. 2002;29(10):1455-62. https:// doi.org/10.1188/02.ONF.1455-1462.

18. Klein DA, Paradise SL, Goodwin ET. Caring for transgender and genderdiverse persons: what clinicians should know. Am Fam Physician. 2018; 98(11):645-53.

19. Diversity in Medicine. Facts and Figures 2019 Executive summary. Washington, D.C.: Association of American Medical Colleges; 2019.

20. Amoli MA, Flynn JM, Edmonds EW, Glotzbecker MP, Kelly DM, Sawyer JR Gender differences in pediatric Orthopaedics: what are the implications for the future workforce? Clin Orthop Relat Res. 2016;474(9):1973-8. https://doi. org/10.1007/s11999-016-4984-z

21. Lautenberger D, Dandar $V$, Raezer C, Sloane RA. The state of women in academic medicine : the pipeline and pathways to leadership, 2013-2014. Washington, D.C: Association of American Medical Colleges; 2014.

22. Ibarra H, Carter NM, Silva C. Why men still get more promotions than women. Harv Bus Rev. 2010;88(9):80-5 126.
23. Brown MEL, Hunt GEG, Hughes F, Finn GM. 'Too male, too pale, too stale': a qualitative exploration of student experiences of gender bias within medical education. BMJ Open. 2020;10(8):e039092.

24. Plank-Bazinet JL, Heggeness ML, Lund PK, Clayton JA. Women's careers in biomedical sciences: implications for the economy, scientific discovery, and Women's health. J Women's Health (Larchmt). 2017;26(5):525-9. https://doi. org/10.1089/jwh.2016.6012

25. Carnes M, Morrissey C, Geller SE. Women's health and women's leadership in academic medicine: hitting the same glass ceiling? J Women's Health (Larchmt). 2008;17(9):1453-62. https://doi.org/10.1089/jwh.2007.0688.

26. Bouck Z, Ferguson J, Ivers NM, Kerr EA, Shojania KG, Kim M, Cram P, Pendrith C, Mecredy GC, Glazier RH, Tepper J, Austin PC, Martin D, Levinson W, Bhatia RS. Physician characteristics associated with ordering 4 low-value screening tests in primary care. JAMA Netw Open. 2018;1(6):e183506. https://doi.org/10.1001/jamanetworkopen.2018.3506.

27. Tsugawa $Y$, Jena AB, Figueroa JF, Orav EJ, Blumenthal DM, Jha AK. Comparison of hospital mortality and readmission rates for Medicare patients treated by male vs female physicians. JAMA Intern Med. 2017; 177(2):206-13. https://doi.org/10.1001/jamainternmed.2016.7875.

28. Ferguson MK, Farnan J, Wroblewski K, Huisingh-Scheetz M, Thompson K. Do estimates of treatment risk based on clinical vignettes differ by physician gender? Ann Thorac Surg. 2018;106(6):1868-72. https://doi.org/10.1016/j.a thoracsur.2018.07.025

29. Maas AH, Appelman YE. Gender differences in coronary heart disease. Neth Heart J. 2010;18(12):598-602. https://doi.org/10.1007/s12471-010-0841-y.

30. Langabeer JR, Henry TD, Fowler R, Champagne-Langabeer T, Kim J, Jacobs AK. Sex-based differences in discharge disposition and outcomes for STsegment elevation myocardial infarction patients within a regional network. J Women's Health (Larchmt). 2018;27(8):1001-6. https://doi.org/10.1089/ jwh.2017.6553.

31. Rathore SS, Chen J, Wang Y, Radford MJ, Vaccarino V, Krumholz HM. Sex differences in cardiac catheterization: the role of physician gender. JAMA. 2001;286(22):2849-56. https://doi.org/10.1001/jama.286.22.2849.

32. Daugherty SL, Blair IV, Havranek EP, et al. Implicit Gender Bias and the Use of Cardiovascular Tests Among Cardiologists. J Am Heart Assoc. 2017;6(12): e006872. https://doi.org/10.1161/JAHA.117.006872.

33. Link JC, Reue K. Genetic basis for sex differences in obesity and lipid metabolism. Annu Rev Nutr. 2017;37(1):225-45. https://doi.org/10.1146/a nnurev-nutr-071816-064827.

34. Hemphill ME, Maher Z, Ross HM. Addressing gender-related implicit Bias in surgical resident physician education: a set of guidelines. J Surg Educ. 2020; 77(3):491-4. https://doi.org/10.1016/j.jsurg.2019.12.014.

35. Hirsh AT, Hollingshead NA, Matthias MS, Bair MJ, Kroenke K. The influence of patient sex, provider sex, and sexist attitudes on pain treatment decisions. J Pain. 2014;15(5):551-9. https://doi.org/10.1016/j.jpain.2014.02.003.

36. Armstrong R, Hall BJ, Doyle J, Waters E. Cochrane update. 'Scoping the scope' of a cochrane review. J. Public Health (Oxf). 2011;33(1):147-50. https://doi.org/10.1093/pubmed/fdr015.

37. Arksey H, O'Malley L. Scoping studies: towards a methodological framework. Int J Soc Res Methodol. 2007;8(1):19-32

38. Tricco AC, Lillie E, Zarin W, O'Brien KK, Colquhoun H, Levac D, Moher D, Peters MDJ, Horsley T, Weeks L, Hempel S, Akl EA, Chang C, McGowan J, Stewart L, Hartling L, Aldcroft A, Wilson MG, Garritty C, Lewin S, Godfrey CM, Macdonald MT, Langlois EV, Soares-Weiser K, Moriarty J, Clifford T, Tunçalp Ö, Straus SE. PRISMA extension for scoping reviews (PRISMA-SCR): checklist and explanation. Ann Intern Med. 2018;169(7):467-73. https://doi.org/10.732 6/M18-0850.

39. Munn Z, Peters MDJ, Stern C, Tufanaru C, McArthur A, Aromataris E. Systematic review or scoping review? Guidance for authors when choosing between a systematic or scoping review approach. BMC Med Res Methodol. 2018;18(1):143. https://doi.org/10.1186/s12874-018-0611-x.

40. Furnas HJ, Garza RM, Li AY, Johnson DJ, Bajaj AK, Kalliainen LK, Weston JS, Song DH, Chung KC, Rohrich RJ. Gender differences in the professional and personal lives of plastic surgeons. Plast Reconstr Surg. 2018;142(1):252-64. https://doi.org/10.1097/PRS.0000000000004478.

41. Greene J, Hibbard JH, Sacks RM. Does the race/ethnicity or gender of a Physician's name impact patient selection of the physician? J Natl Med Assoc. 2018;110(3):206-11. https://doi.org/10.1016/j.jnma.2017.05.010.

42. Berthold HK, Gouni-Berthold I, Bestehorn KP, Böhm M, Krone W. Physician gender is associated with the quality of type 2 diabetes care. J Intern Med. 2008;264(4):340-50. 
43. Hamberg K, Risberg G, Johansson EE. Male and female physicians show different patterns of gender bias: a paper-case study of management of irritable bowel syndrome. Scand J Public Health. 2004;32(2):144-52.

44. Bernardes SF, Costa M, Carvalho H. Engendering pain management practices: the role of physician sex on chronic low-back pain assessment and treatment prescriptions. J Pain. 2013;14(9):931-40.

45. Sabin J, Nosek BA, Greenwald A, Rivara FP. Physicians' implicit and explicit attitudes about race by MD race, ethnicity, and gender. J Health Care Poor Underserved. 2009;20(3):896-913.

46. Schwartz MB, Chambliss HO, Brownell KD, Blair SN, Billington C. Weight bias among health professionals specializing in obesity. Obes Res. 2003;11(9): 1033-9.

47. Glick P, Fiske ST. The Ambivalent Sexism Inventory: Differentiating Hostile and Benevolent Sexism. J Pers Soc Psychol. 1996;70(3):491-512.

48. Avant ND, Weed E, Connelly C, Hincapie AL, Penm J. Qualitative Analysis of Student Pharmacists' Reflections of Harvard's Race Implicit Association Test. Curr Pharm Teach Learn. 2018;10(5):611-7.

49. Butkus R, Serchen J, Moyer DV, Bornstein SS, Hingle ST. Physicians HaPPCotACo. Achieving gender equity in physician compensation and career advancement: a position paper of the American College of Physicians. Ann Intern Med. 2018;168(10):721-3. https://doi.org/10.7326/M 7-3438.

50. Dehon E, Weiss N, Jones J, Faulconer W, Hinton E, Sterling S. A systematic review of the impact of physician implicit racial Bias on clinical decision making. Acad Emerg Med. 2017;24(8):895-904. https://doi.org/10.1111/a cem.13214.

51. Carnes $M$, Devine $P G$, Isaac C, Manwell LB, Ford CE, Byars-Winston A, Fine E, Sheridan J. Promoting institutional change through Bias literacy. J Divers High Educ. 2012;5(2):63-77. https://doi.org/10.1037/a0028128.

52. White AA, Logghe HJ, Goodenough DA, Barnes LL, Hallward A, Allen IM, et al. Self-awareness and cultural identity as an effort to reduce Bias in medicine. J Racial Ethn Health Disparities. 2018;5(1):34-49. https://doi.org/1 0.1007/s40615-017-0340-6.

53. Baggio JA, Freeman J, Coyle TR, Nguyen TT, Hancock D, Elpers KE, Nabity S, Dengah II HJF, Pillow D. The importance of cognitive diversity for sustaining the commons. Nat Commun. 2019;10(1):875. https://doi.org/10.1038/s41467019-08549-8.

54. Hansen M, Schoonover A, Skarica B, Harrod T, Bahr N, Guise JM. Implicit gender bias among US resident physicians. BMC Med Educ. 2019;19(1):396. https://doi.org/10.1186/s12909-019-1818-1.

\section{Publisher's Note}

Springer Nature remains neutral with regard to jurisdictional claims in published maps and institutional affiliations.

Ready to submit your research? Choose BMC and benefit from:

- fast, convenient online submission

- thorough peer review by experienced researchers in your field

- rapid publication on acceptance

- support for research data, including large and complex data types

- gold Open Access which fosters wider collaboration and increased citations

- maximum visibility for your research: over $100 \mathrm{M}$ website views per year

At $\mathrm{BMC}$, research is always in progress.

Learn more biomedcentral.com/submissions 